\title{
ESCRIBIR OU PASAR O FERRO: UNHA ANÁLISE FEMINISTA DOS DILEMAS ENTRE A VIDA PROFESIONAL E OS ROLES DAS MULLERES EN MARÍA VICTORIA MORENO
}

\author{
TO WRITE OR DO THE IRONING: A FEMIIIIST ANALYSIS OF THE DILEMMAS \\ BETWEEN PROFESSIONAL LIFE AND ROLES OF WOMEN IN MARÍA VICTORIA MORENO \\ Marilar Aleixandre
}

Deixei de escribir por pasar o ferro,

deixei de escribir por cociñar.

María Victoria Moreno, Diario de Pontevedra, 2005

\section{TENSIÓNS ENTRE A VIDA PROFESIONAL DAS MULLERES E AS ANGUEIRAS DOMÉSTICAS}

Escribir ou pasar o ferroํ. Deixar de escribir por cociñar. En 2018 celebramos as contribucións de María Victoria Moreno á lingua e a literatura galega, como escritora e como activista a prol da lingua. Estas contribucións leváronse a cabo en circunstancias non sempre doadas. As tensións entre a vida profesional ou artística e as angueiras domésticas son unha constante na experiencia das mulleres, e non só na da autora homenaxeada o Día das Letras.

Neste ano de 2018 o Consello da Cultura Galega realizou unha edición facsimilar do primeiro libro publicado por María Victoria en 1973, Mar adiante (Moreno 2018), xunto cun mecanoscrito ilustrado por ela e conservado por Sara Alonso Pimentel, a quen estaba dedicado. Esta publicación fai posíbel lembrar que a belísima portada de Mar adiante é obra de Carmen Arias Castro, Mimina, autora -non sempre recoñecida - de deseños das cerámicas d'O Castro e Sargadelos. Carmen Arias viu interrompidos os estudos de Belas Artes pola maternidade dos seus fillos

1 Unha versión abreviada deste traballo foi lida no Acto do Día das Letras dedicado a María Victoria Moreno, en Pontevedra o 17 de maio de 2018. 
con Isaac Díaz Pardo. Hai numerosos exemplos de mulleres que experimentaron atrancos semellantes, entre os que se poden citar dous bicentenarios conmemorados en 2018: Mary Shelley ocupouse dos cinco fillos que tivo con Percy Shelley e mesmo de pasar a limpo os poemas del, mentres escribía Frankenstein, libros de viaxes e outras novelas. Jenny von Westphalen criou sete fillos, lidou cos acredores e dedicou moitas horas a transcribir a ilexíbel escritura de Karl Marx, ademais de discutir con el ideas teóricas e compoñer os seus propios ensaios (Aleixandre 2018). Jenny escribiu que mesmo nos círculos socialistas, atendíase aos dereitos dos homes e non aos dereitos e necesidades das mulleres. Son dilemas reflectidos na narrativa de María Victoria Moreno e nos seus textos autobiográficos. Neles emerxe o conflito entre ideas a favor da igualdade entre mulleres e homes e o papel de ama de casa que se demanda delas.

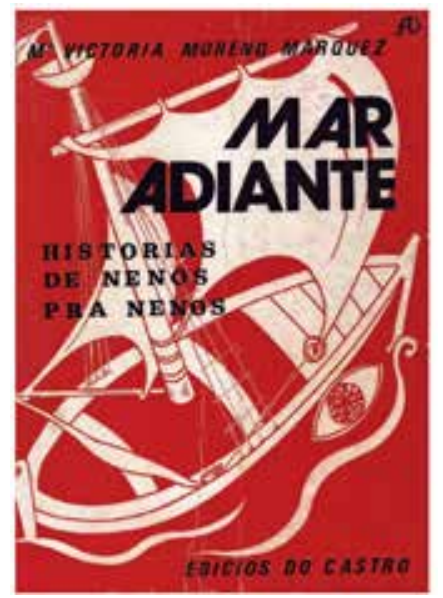

Portada de Carmen Arias da primeira edición de Mar adiante, Real Academia Galega

Neste traballo analízase a tensión entre a vida profesional como escritora e os roles atribuídos socialmente ás mulleres, tanto desde o punto de vista biográfico como na obra de María Victoria Moreno. A análise está enmarcada na crítica literaria feminista que leva a cabo unha reflexión, entre outras dimensións, sobre o contexto e as condicións de produción da obra literaria das mulleres. Pódese dicir que a crítica literaria feminista nace co libro de Kate Millett Sexual Politics (1970), pioneira en desvelar o sesgo patriarcal nas manifestacións culturais. Sen entrar no debate sobre o modo en que o libro, e a tese de doutoramento da autora na que está baseado, utiliza a psicanálise freudiana, cómpre recoñecer que Millett é a primeira en fornecer unhas "lentes violetas" para examinar a literatura, para identificar manifestacións da ideoloxía patriarcal na narrativa, até ese momento considerada un terreo "neutro". A título persoal podo sinalar o impacto causado en min pola súa lectura en 1971 -logo de mercar a primeira edición inglesa nunha 
viaxe a Londres, pois neses tempos non era posíbel encargar libros por Internet, que non existía, libros dos que con frecuencia só coñeciamos a publicación grazas ás librarías feministas-, e como desde ese momento dispuxemos dunha ferramenta para "ler" doutro modo. Esta crítica feminista permite identificar como contribúen dimensións específicas da cultura ao proceso polo que, en palabras de Simone de Beauvoir (1949 / 2008) “se chega a ser muller", o que Beauvoir opón á afirmación "non se nace muller". Nese sentido, como sinala Iris Zavala (1993), os propósitos da crítica feminista van máis alá do estritamente académico, encaminándose a modificar a realidade social ao modificar as representacións; interpretacións e estratexias que "nos permiten desmitificar y ayudan a identificar las autoridades que hacen posibles las exclusiones, las desigualdades, los silencios, las marginaciones, las mitologías de superioridad, las identificaciones e identidades limitadas" (1993: 48). Para Puri Mayobre (2002) as modificacións emprendidas pola crítica feminista son un xiro epistemolóxico, que leva a cabo unha deconstrución do androcentrismo na raíz das prácticas culturais e unha reconstrución da perspectiva das mulleres. Amelia Valcárcel (1991) sitúa o camiño iniciado por Simone de Beauvoir na restitución ás mulleres do logos, do discurso. Este traballo pretende contribuír a esta identificación de exclusións e desigualdades das mulleres, especificamente das mulleres escritoras, que nalgúns casos conducen ao silencio.

\section{ESCRIBINDO NA COCIÑA EN TEMPOS ROUBADOS: O CONFLITO NOS TEXTOS BIOGRÁFICOS DE MARÍA VICTORIA MORENO}

No ensaio As linguas de España, publicado en 1991, María Victoria compara a situación de discriminación das mulleres coa da lingua galega: "Na sociedade de predominio masculino en que vivimos, aínda hoxe, a muller é considerada coma cidadá de segundo rango e, en certos ambientes, recibe un tratamento semellante ó que rematamos de describir verbo das linguas nativas" (1991: 63).

Unha diferenza entre mulleres e homes moi relevante para o oficio de escribir é o tempo dispoñíbel. A socióloga María Ángeles Durán (2010) calculou que a xornada media semanal dun varón español, excluíndo vacacións e festivos, é de 36 horas e 43 minutos, e a dunha muller de 56 horas e sete minutos. Virginia Woolf (1929) sinalou en Un cuarto de seu a necesidade das mulleres dispoñer dun cuarto propio, primeira condición para poderen escribir. Mais tamén é preciso contar cun tempo propio (Aleixandre 2003). Woolf chamou o "Anxo do Fogar" ao espectro que se interpoñía entre ela e o papel ou bisbaba desde as súas costas impedíndolle escribir; un anxo que sobranceaba "nas difíciles artes da vida familiar".

Malia a falta de tempo e cuarto de seu non ser un atranco exclusivo da autora, outras escritoras non o expresaron tan explicitamente. María Victoria alude en 
ensaios, cartas e entrevistas tanto ao espazo para escribir como ao tempo, e mesmo á imaxe que as mulleres teñen de si mesmas, á representación do que conciben como os seus deberes de anxo do fogar. De cuarto propio para escribir careceu durante moitos anos. Escribía a man na mesa da cociña, á luz dun flexo verde (Casalderrey/Aleixandre 2018). Despois pasábao a máquina, en palabras da súa filla Begoña, "en calquera sitio que estivese libre". $\bigcirc$ único despacho que existía na casa estaba ocupado polo seu home José Luis Llácer. Talvez procurase espazo e tempo para si mesma nas breves estadías, na primavera de 1994 e febreiro de 1995, coas monxas do mosteiro cisterciense de Ferreira de Pantón. En 1986 acadou a praza de catedrática de Instituto en Vilalonga, onde ensinou até 1990, ano en que puido trasladarse a Pontevedra. Logo de ir e vir diariamente desde Pontevedra algúns meses, alugou un apartamento en Sanxenxo o que, entendemos, lle permitiu dispoñer de tempo e acougo para escribir a súa novela máis elaborada, Anagnórise, publicada en 1988 e dedicada a "os meus alumnos de Vilalonga". Unicamente despois da morte de José Luis, en 1996, puido utilizar María Victoria o despacho.

A ausencia de espazo propio, destinado a escribir, reflicte -neste como noutros casos- unha xerarquía entre o rol de ama de casa e o de escritora (ou mesmo de profesora), implicitamente considerado unha actividade que sería posíbel realizar en "calquera sitio que estivese libre" a tempos perdidos ou roubados ao sono. Nesta xerarquía relaciónanse espazos, tempos e o espectro do Anxo do Fogar, como mostra a tarxeta manuscrita que María Victoria envía á Asociación O Facho o 14 de maio de 1975, parte da correspondencia sobre a conferencia que ía impartir o 25: "Meus amigos: envíolles curriculum e máis guión. Todo vai escrito a man porque son neste intre as tres da mañán e non podo despertar coa máquina á miña filla nin á rapazada dos veciños. Perdón”.

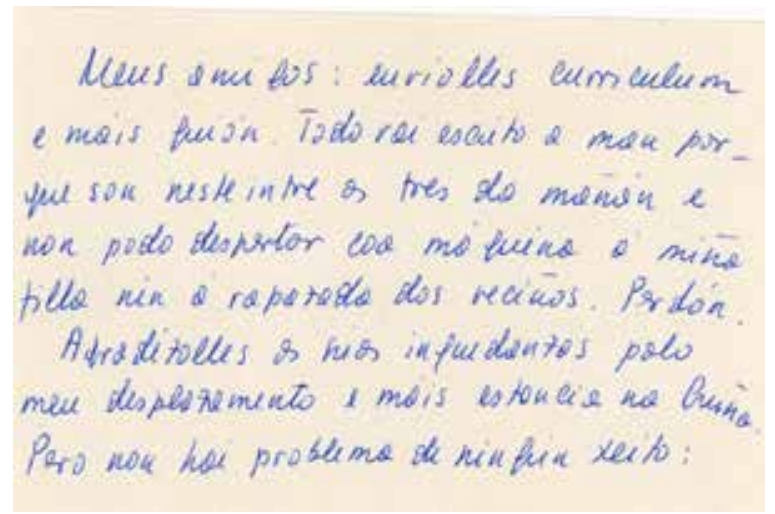

Tarxeta de María Victoria a O Facho. 14 de maio de 1975. Real Academia Galega 
Adoitaba María Victoria escribir de madrugada, neste caso ás tres da mañá, por ser as horas nas que podía dedicar á escrita un tempo continuado, ao que se pode engadir que durmía moi pouco. A tarxeta reflicte, asimesmo, que toda a casa é un espazo no que escribir está subordinado ao benestar do resto da familia, os fillos e mesmo a veciñanza. Evidénciase nela o conflito entre tempo -unicamente é posíbel escribir a altas horas da noite- e espazo-fogar, no que os ruídos de madrugada, como o trecolear da máquina, son inaceptábeis. María Victoria non pode escribir a outra hora e a estas horas non pode utilizar a máquina de escribir.

A falta de tempo para escribir -para ler e mesmo para o sono- é recorrente en textos autobiográficos, como O diario da luz e a sombra (2004):

hai algúns anos, cando eu tiña ó meu coidado unha familia de tres xeracións, cos problemas e angueiras que esixen as tres idades, e traballaba a vinte e cinco quilómetros da casa, chamaba ós domingos vésperas de luns. Anguriábanme aquelas tardes de domingo en que sempre agardaba por min unha lavadora, un cesto de roupa para pasarlle o ferro e mais a comida do luns, que había que deixar feita para manter os horarios e a calidade de vida dunha familia ordenada.

Naqueles tempos pasados arelaba horas de lecer porque non as tiña e arelaba así mesmo momentos de soidade para a lectura e a reflexión porque as tarteiras, as lavadoras, o ferro de pasar e o supermercado ocupábanme mesmo o tempo que debía adicar ó sono e ó descanso (Moreno 2004: 69).

A familia de tres xeracións fai referencia á intensa dedicación de María Victoria a coidar dos seus. Entre 1983 e 1996, ademais de se ocupar dos fillos, coida da súa nai. Como indican Soto e Senín (2018) "Rodeada de tarteiras, lavadoras e o ferro de pasar, gustáballe dicir que un bo día saíra da cociña para facer outras cousas".

O conflito entre escribir e as tarefas da casa é máis explícito na entrevista de María Varela no Diario de Pontevedra, en xaneiro de 2005, reproducida de novo en xuño de 2017, logo da elección pola RAG de María Victoria como homenaxeada nas Letras Galegas:

Fixen ben o meu traballo, fixen, penso que moi ben o da casa. Tiven a miña nai doce anos comigo con problemas de senilidade fortes, coidei ó meu home ata que a morte nos separou, eduquei dous fillos, púxenlles os medios necesarios para que chegasen ata onde eles quixesen chegar, deixei de escribir por pasar o ferro, deixei de escribir por cociñar... (Varela 2005). 
Na entrevista ponse de manifesto como no dilema entre escribir e os coidados, o traballo da casa, é a escrita a que perde. A esas "outras actividades" atribúe a autora non escribir máis, chegando a afirmar "Non son escritora", ao tempo que identificaba a Xavier Senín como a persoa que "me sacou da cociña": "Non son escritora porque a maior parte do meu tempo dedícoa a outras actividades, pese a que teño a Xavier Senín, coma un anxo da garda pertinaz e xeneroso, dicindo escribe, escribe, escribe..." (Moreno 1994).

\section{AS IDEAS DE IGUALDADE E OS ROLES DAS MULLERES NA NARRATIVA DA AUTORA}

A tensión entre as ideas de igualdade e os papeis tradicionalmente atribuídos ás mulleres emerxen asimesmo na narrativa de María Victoria Moreno. Nalgúns casos, sen dúbida con boa intención, afírmase de María Victoria que era feminista. Cómpre matizar que esta é unha etiqueta que ela mesma nunca se atribuíu e coa que probabelmente non se identificaría. Hai unhas décadas o feminismo era contemplado con receo por unha parte considerábel da sociedade, sendo a mudanza social sobre esta cuestión moi notábel nos últimos anos; nos 70, 80 e mesmo 90 as identificadas como feministas eramos unha minoría. Sinalemos que non se trata de aplicar uns ou outros criterios para asignar esta condición -hai moitos feminismos e distintas formas de ser feminista- senón de como unha persoa, unha muller, se identifica a si mesma, en que medida considera ser feminista parte da súa identidade. No caso da autora é preciso distinguir entre, por unha banda, a defensa da igualdade, as ideas feministas explícitas en varias das súas obras e implícitas noutras e, por outra, a adscrición ao feminismo, no que non estivo implicada. María Victoria foi moi clara ao falar das causas nas que se comprometeu activamente, como a defensa do galego. Tamén se expresou de forma inequívoca, e mesmo con vehemencia, en contra da linguaxe inclusiva, presentándose a si mesma como "son un home de ben". Suxiro ler as súas obras en contexto e valorar no que nelas hai de ideas a prol da igualdade, os conflitos que revelan entre os múltiples roles que se demandan das mulleres, ou que as mulleres se demandan a si mesmas. As tensións, segundo os enfoques dialécticos, son un dos motores que fan cambiar o mundo.

O cataventos, conto co que acada o premio O Facho en 1975 -o seu primeiro galardón- é un canto á liberdade e unha crítica ao machismo. A tiranía do galo don Pío asoballa, ademais das galiñas, os paxariños da contorna. A Pombapitiña chega ao galiñeiro sen coñecer os seus costumes e desafía a autoridade de don Pío, choutando máis alto ca el. O galo adoece coa envexa: 
Eu son o que manda eiquí

i esa parva de galiña

voa máis alto ca min

Pois o galo é o único personaxe que fala en verso. O castigo para a Pombapitiña é cruel: será depenada polas Teixaspitiñas, un coro no que María Victoria simboliza a submisión feminina, repetindo "e a moita honra o servir". Porén, as plumas da Pombapitiña cravadas nas ás de don Pío non fan que voe máis alto, ao contrario, pesan como chumbo e déixano espetado no cumio do tellado, convertido no cataventos do título.

De certo, a obra da autora na que a crítica á discriminación e ás representacións sociais sobre as mulleres resulta máis explícita é Anagnórise (1988), unha novela moi conseguida. É a historia da viaxe iniciática de Nicolau, un mozo de dezasete anos fuxindo dun desengano amoroso e da situación de desesperanza na casa logo de morrer unha irmá. Nicolau leva consigo uns paquetes de haxix. Recollido cando fai autostop por unha misteriosa muller, o seu anoxo inicial vai mudando ao longo da viaxe. Ao comezo Nicolau expresa toda unha serie de prexuízos sobre as mulleres: "As tías non saben conducir. As tías non paran para coller a ninguén. Coas tías non se pode contar para nada. Ándanche polo mundo con medo a todo [...]. As mulleres son parvas e amais moi metidas" (1988: 11).

Mais durante a viaxe ela vai desarmando os seus estereotipos:

- Porque as mulleres, xa se sabe...

- Xa se sabe, xa se sabe... As mulleres -apón ela incomodada- son persoas coma as demais.

- Pero para conducir...

- Para conducir e para todo.

- Pois todo o mundo di que conducen con máis seguridade os homes.

- Non che vou negar que a maior parte dos homes teñan máis experiencia, pero iso débese a que as mulleres son vítimas dunha marxinación inxusta que as afasta de moitas actividades.

- Refírese ós traballos da casa?

- Refírome, logo.

- E quen ía facelos se non os fixesen as mulleres? (1988: 19).

Nesta novela, arriscada e pouco convencional, Nicolau vai mudando moitas das súas ideas, tanto sobre as mulleres como sobre si mesmo.

Hai libros nos que se manifesta o outro polo do dilema, representando as mulleres ou as nais dos protagonistas como persoas temerosas, cun papel reducido a 
coidar da casa. En Leonardo e os fontaneiros, Antón, dirixíndose ao can Leonardo, describe a súa nai como unha "caguiñas", en contraste co pai: "Porque a nai, xa sabes, non ten azos para nada e se por ela fose pasabámo-la vida anguriados pola calor, polo frío, pola saúde, polas notas... Por todo. Pero o pai é outra cousa” (1990: 108).

Excepcións a estas imaxes medoñentas son as mestras de Mar adiante e Onde o aire non era brisa, e sobre todo a Xulia Andrade de Anagnórise, unha muller libre, destemida, que ten moito da autora.

A festa no faiado (1986) é un exemplo de ambivalencia. Por unha banda a boneca Uxía ten un papel activo na mudanza do faiado dunha morea de refugallos a unha festa chea de ledicia; pola outra o seu papel é o tradicionalmente asignado ás mulleres, cociñar, os coidados. Como analizan Soto e Senín:

É a boneca a encargada de provocar un cambio, dada a súa maior experiencia, sabedoría e coñecemento dos costumes dos humanos, a que se arrisca a traspasar os límites impostos, por máis que asuma un rol feminino tradicional e se ocupe de cociñar e de cubrir as necesidades afectivas dos que a arrodean, e a que consegue transformar a tristura do inicio en alegría, o que reafirma a busca da felicidade como o leitmotiv do conto (2018: 118).

\section{A MODO DE CONCLUSIÓN}

Un aspecto da narrativa de María Victoria e tamén da súa biografía, que excede o propósito deste artigo, é a súa paixón polos animais, especialmente polos cans, analizada por Casalderrey e Aleixandre (2018). Sempre tivo un ou máis cans, Alma, Nico ou Nica, e moitos deles convertéronse en personaxes dos seus libros, Leonardo mesmo en protagonista do título. En Anagnórise hai unha denuncia explícita dos que se comportan de modo cruel cos animais, unha defensa de que os animais senten e sofren como as persoas. Esta consideración polos animais pode contemplarse á luz da filosofía poshumanista, do feminismo de autoras como Rosi Braidotti (2016) e Angélica Velasco (2017). Braidotti, nun capítulo que por cortesía da autora foi publicado en Grial na tradución ao galego antes da súa publicación en inglés, critica o humanismo de base ilustrada que concibía a orde natural como servidume e violencia, e a natureza como xustificación das desigualdades. Partindo das críticas feministas, poscoloniais e ecoloxistas á oposición subxectividade -alteridade como práctica discursiva, unha violencia epistémica na que ser diferente (mulleres, indíxenas e outros seres da terra) é sinónimo de ser inferior-, Braidotti propón un feminismo poshumanista baseado na descentralización de Antropos na mudanza cara a Zoe, a vida no seu conxunto, especialmente a dos animais e outros 
seres non humanos. Angélica Velasco (2017) relaciona a indiferenza ante o sufrimento das mulleres, ante a violencia exercida contra as mulleres, coa indiferenza ante o sufrimento dos animais. Propón ampliar a ética, considerando a relevancia moral dos animais, e incluír a defensa dos animais como unha cuestión feminista. Nesta perspectiva, a obra de María Victoria é sen dúbida un exemplo de consideración polos animais como suxetos de dereitos e obxecto de afectos. Noutro traballo (Aleixandre 2019) abordo a cuestión da identificación cos animais na poesía galega.

Os libros de María Victoria Moreno contribúen a desarmar estereotipos, a mudar representacións sociais que limitan os roles e actividades das mulleres. Os seus escritos autobiográficos revelan o modo en que ela, como moitas mulleres neses anos e aínda hoxe, se viu obrigada a escoller entre pasar o ferro ou escribir, a deixar de escribir por pasar o ferro. Malia estes atrancos, María Victoria foi quen de elaborar unha obra narrativa e ensaística de grande calidade, a contribuír coa súa escrita e co seu compromiso á causa da lingua galega e á consolidación da literatura infantil e xuvenil. Isto en tempos roubados ao sono e á cociña, en calquera espazo onde puidese encontrar un mínimo acougo. Temos a esperanza, que María Victoria de certo compartiría, de que cada vez sexan menos as mulleres que deban se enfrontar a eses dilemas.

\section{AgradeCEMentos:}

Á Asociación O Facho, que fixo doazón do seu valioso arquivo á Real Academia Galega, o que permitiu consultar a correspondencia entre María Victoria Moreno e O Facho. A Begoña Llácer, filla de María Victoria, sempre disposta a proporcionar informacións. A Fina Casalderrey, polas súas ideas e suxestións. Ao proxecto "Ecoficcións", financiado polo MINECO-FEDER, código FEM2015-66937-P.

\section{REFERENCIAS BIBLIOGRÁFICAS}

Aleixandre, Marilar (2003): "Arrebolarlle un tinteiro á cabeza", en Belén Fortes (coord.), Escrita e mulleres: doce ensaios arredor de Virginia Woolf. Santiago de Compostela: Sotelo Blanco, [139]-143.

(2018): "Douscentos anos de Karl Marx, douscentos catro de Jenny von Westphalen”, Sermos Galiza 10/V/2018.

(2019): "As focas teñen ollos de muller, as deusas ollos de vaca: identificación animal na poesía nun continuo humano-non humano", en Manuel Magán Abollo (dir.), A época do espazo: Estado e novas perspectivas (Santiago 
de Compostela, 8-9 de abril de 2019). Santiago de Compostela: Universidade. Conferencia plenaria no congreso.

Beauvoir, Simone de (1949 / 2008): Le deuxième sexe. Paris: Gallimard. Tradución ao galego de Marga R. Marcuño: O segundo sexo. Vigo: Edicións Xerais de Galicia, 2008.

Braidotti, Rosi (2016): "Catro teses verbo do feminismo posthumano", Grial 211, 138-153. Tradución: Eva Almazán. Ed. orixinal: "Four theses on posthuman feminism", en Richard Grusin (ed.), Anthropocene feminism. Minneapolis, MN: University of Minessota Press, 21-48, 2017.

Casalderrey, Fina e Marilar Aleixandre (2018): María Victoria Moreno: a muller que durmía pouco e soñaba moito. Vigo: Edicións Xerais de Galicia.

Durán, María Ángeles (2010): Tiempo de vida y tiempo de trabajo. Bilbao: Fundación BBVA.

Mayobre, Purificación (2003): "Teorías literarias feministas: (Con)textos [Introducción]”, en Beatriz Suárez Briones, Sextualidades. Teorías literarias feministas. Alcalá de Henares: Ayuntamiento / Centro Asesor de la Mujer.

Millett, Kate (1972): Sexual Politics. London: Sphere books. (1를. ed.: Garden City, NY: Doubleday \& Company, 1970).

Moreno, María Victoria (1979): "O cataventos", en Contos pra nenos. Vigo: Galaxia. (Reed. Santiago de Compostela: Urco Editora, 2017). (1986): A festa no faiado. Vigo: Galaxia. (1988): Anagnórise. Vigo: Galaxia.

(1990): Leonardo e os fontaneiros. Vigo: Galaxia. (1를 ed.: Vigo: Galaxia / SM, 1986).

(1991): As linguas de España. Santiago de Compostela: Xunta de Galicia. (1994): “iEscritora alófona eu?" en Xesús Alonso Montero e Xosé Manuel Salgado (eds.), Poetas alófonos en lingua galega: actas do I congreso. Santiago de Compostela, abril de 1993. Vigo: Galaxia, 107-111. (2004): Diario da luz e a sombra. Vigo: Edicións Xerais de Galicia. (2018): Mar adiante. Santiago de Compostela: Consello da Cultura Galega, [17]-36. Edición facsímile. Dispoñíbel en http://consellodacultura.gal/ publicacion.php?id=4318 . (1 $1^{\mathrm{a}}$ ed.: Sada: Ediciós do Castro, 1973).

Soto, Isabel, e Xavier Senín (2018): María Victoria Moreno. Sementadora de futuro. Vigo: Edicións Xerais de Galicia.

Valcárcel, Amelia (1991): Sexo y filosofía: sobre "mujer" y "poder". Barcelona: Anthropos. 
Varela, María (2005): "María Victoria Moreno, unha principiña de sal e pementa [entrevista, I/2005]", Diario de Pontevedra 18/VI/2017. Dispoñíbel en https:// www.diariodepontevedra.es/articulo/cultura/maria-victoria-moreno-unha-principina-de-sal-e-pementa/20170618000000330482.html

Velasco Sesma, Angélica (2017): La ética animal, iuna cuestión feminista? Madrid: Cátedra.

Woolf, Virginia (1929 /2005): A room of one's own. London: Hogarth Press. Tradución ao galego de Iria Sobrino: Un cuarto de seu. Santiago de Compostela: Sotelo Blanco, 2005.

Zavala, Iris (1993): "Las formas y funciones de una teoría crítica feminista. Feminismo dialógico", en Myriam Díaz-Diocaretz e Iris M. Zavala (eds.), Breve historia feminista de la literatura española (en lengua castellana). Vol I. Teoría feminista: discursos y diferencias. Barcelona: Anthropos, 27-79. 